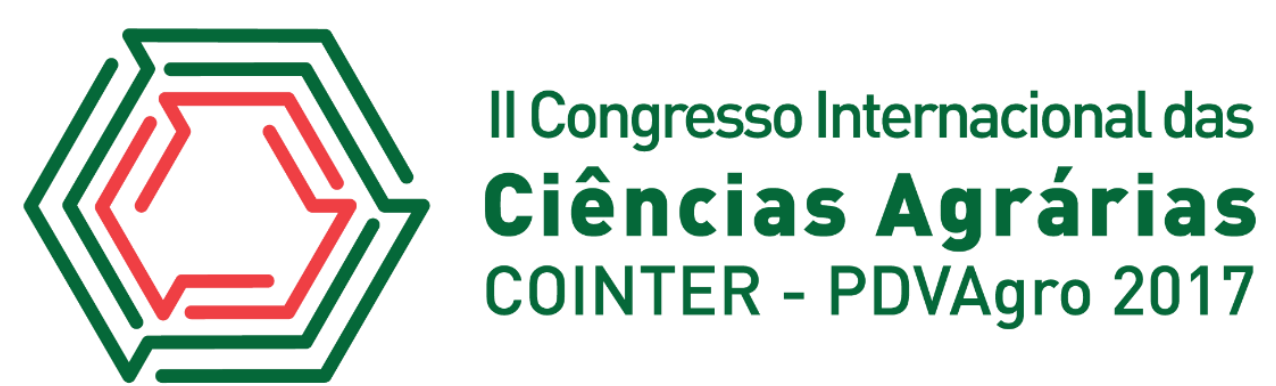

\title{
CARACTERIZAÇÃO E AVALIAÇÃO DE FRUTOS EM ACESSOS DE AÇAIZEIRO DO TIPO BRANCO.
}

\author{
Apresentação: Pôster
}

Hugo Felipe Santa Brigida do Nascimento ${ }^{1}$; Maria do Socorro Padilha de Oliveira ${ }^{2}$.

\section{Introdução}

O açaizeiro (Euterpe oleracea Mart.) é nativo da Amazônia brasileira ocorrendo vários tipos em abundância no Pará, que se apresenta como o principal centro de dispersão natural dessa palmácea, como é o caso do tipo branco (NOGUEIRA et al, 2005). Os frutos do tipo branco são poucos conhecidos e alcançam os mercados regional e nacional, pois para esse tipo de açaí há poucas informações disponíveis. Esses mercados têm estimulado muitos produtores no seu cultivo em escala comercial, inclusive em outros estados do Brasil, como também, o manejo de suas populações naturais (OLIVEIRA \& FARIAS NETO, 2004). A produção de frutos, que provinha quase que exclusivamente do extrativismo, a partir da década de 1990, passou a ser obtida também de açaizais nativos manejados e de cultivos realizados em áreas de várzea e de terra firme, em sistemas solteiros e consorciados (OLIVEIRA, 2004). Os frutos são drupas globosas de coloração verde opaca, no caso do tipo branco, possuindo camada esbranquiçada que os envolve, quando maduros, podendo perfilhar ou não (OLIVEIRA et al, 2002). Atividades de avaliação e caracterização morfológica são essenciais no manejo de Bancos e Coleções de Germoplasma, por gerarem informações sobre descrição e a classificação do material conservado, assim como identificar duplicatas e discriminar caracteres. Tais atividades visam subsidiar a identificação de acessos desejáveis ao mercado de polpa e, por conseguinte, a sua domesticação (BRANDÃO, 2014). Este trabalho teve por objetivo avaliar e caracterizar morfologicamente frutos de acessos de açaizeiro do tipo branco conservados na Embrapa Amazônia Oriental.

\footnotetext{
${ }^{1}$ Agronomia, Universidade Federal Rural da Amazônia, hugosantabrigida@gmail.com

2 Pesquisadora Doutora A, Embrapa Amazônia Oriental, socorro-padilha.oliveira@embrapa.br
} 


\section{Fundamentação Teórica}

A avaliação e a caracterização são atividades primordiais na geração de conhecimentos de germoplasma de qualquer espécie, sendo a morfológica a mais usada por gerar informações sobre a descrição e a classificação dos acessos conservados, como também na discriminação de caracteres mais importantes de menor custo (OLIVEIRA, 2001). O objetivo final da produção de frutos de açaí é o aproveitamento da polpa, portanto, a caracterização dos frutos é de fundamental importância na geração de conhecimentos sobre os acessos, já que fornece subsídios para discriminá-los, além de permitir um melhor manejo, e também para o melhoramento genético (CUNHA, 2013).

\section{Metodologia}

Para a realização deste estudo foi colhido um cacho em plena maturação de 15 acessos de açaizeiro do tipo branco, conservados no Banco de Germoplasma da Embrapa Amazônia Oriental. Os cachos foram identificados e levados ao laboratório de fitomelhoramento para serem analisados.

De cada cacho foram retirados ao acaso 10 frutos, sendo mensurados para dez caracteres morfológicos, oito quantitativos e dois qualitativos. Os caracteres quantitativos foram: diâmetros longitudinal (DL) e transversal (DT), peso do fruto (PF), peso da polpa (PP), peso da semente (PS) e espessuras da polpa (EP) e da amêndoa (EA). O rendimento de polpa por acesso (RPA) foi calculado por meio da relação PF/PP*100. Os caracteres qualitativos foram: cor do fruto (CF), cor da polpa (CP). Os caracteres quantitativos foram obtidos por meio de paquímetro e balança de precisão, e os qualitativos por meio de carta de cores (MUNSELL COLOR CHARTS, 1977) e por escala de notas.

Os caracteres quantitativos foram organizados e digitatos em planilha Excel para a obtenção de estatísticas descritivas, envolvendo valores mínimos, máximos, médios. Enquanto os qualitativos foram expressos em porcentagem.

\section{Resultados e Discussão}

Os acessos de açaizeiro tipo branco apresentaram frutos com diâmetros médios de 13,15mm longitudinal e 14,97 mm transversal, sendo que oito deles (2, 12, 23, 30, 34, 36, 47 e 49) tiveram diâmetros médios menores que a média geral para o diâmetro longitudinal (Tabela 1). A média geral para peso do fruto foi de 1,84 g, com sete acessos mostrando médias menores $(2,23,30,34$, 
36, 47 e 49), característica desejável ao mercado de polpa. O rendimento médio da parte comestível foi de 28,60\%, com sete acessos possuindo médias acima desse valor (4, 12, 17, 30, 34, 36, 47 e 49), com destaque para o acesso 1 (Figura 1). Para os demais caracteres quantitativos a média geral foi de 1,32 $\mathrm{g}, 0,68 \mathrm{~mm}$ e 1,82 $\mathrm{mm}$ para o peso da semente e espessuras da polpa e da amêndoa, respectivamente. Com base nos resultados obtidos, pode-se considerar que os frutos dos acessos de açaizeiro do tipo branco avaliados, expressam caracteres morfológicos desejáveis ao mercado de polpa, uma vez que sete deles exibiram peso dos frutos inferiores à média geral, dando a entender que são frutos pequenos e que mais da metade exibiu rendimento de polpa superior à média.

Tabela 1. Médias para os caracteres diâmetro longitudinal (DL), diâmetro transversal (DT), peso do fruto (PF), peso da polpa (PP), rendimento de polpa (RP), peso da semente (PS), espessura da polpa (EP) e espessura da amêndoa em quinze acessos de açaí branco (Euterpe oleracea) conservados no Banco Ativo de Germoplasma da Embrapa Amazônia Oriental. Fonte: Autor.

\begin{tabular}{ccccccccc}
\hline Acessos & DL $(\mathrm{mm})$ & DT $(\mathrm{mm})$ & PF $(\mathrm{g})$ & PP $(\mathrm{g})$ & RP $(\%)$ & PS $(\mathrm{g})$ & EP $(\mathrm{mm})$ & EA $(\mathrm{mm})$ \\
\hline \hline 2 & 12.80 & 14.37 & 1.63 & 0.43 & 26.33 & 1.20 & 0.74 & 1.78 \\
4 & 13.45 & 15.27 & 1.96 & 0.57 & 28.97 & 1.39 & 0.50 & 1.77 \\
6 & 13.88 & 15.75 & 2.10 & 0.58 & 27.42 & 1.52 & 0.74 & 1.83 \\
8 & 13.96 & 16.09 & 2.24 & 0.54 & 24.29 & 1.70 & 0.70 & 2.20 \\
10 & 13.40 & 15.24 & 1.90 & 0.53 & 27.64 & 1.37 & 0.76 & 1.95 \\
12 & 13.04 & 15.01 & 1.92 & 0.59 & 31.04 & 1.32 & 0.582 & 1.82 \\
17 & 13.49 & 15.36 & 2.02 & 0.70 & 34.84 & 1.32 & 0.75 & 1.76 \\
19 & 13.67 & 15.82 & 2.01 & 0.44 & 21.97 & 1.57 & 0.70 & 2.24 \\
23 & 12.21 & 13.89 & 1.47 & 0.42 & 28.46 & 1.05 & 0.63 & 1.68 \\
30 & 13.00 & 14.92 & 1.79 & 0.55 & 30.91 & 1.24 & 0.70 & 1.78 \\
34 & 12.17 & 13.87 & 1.55 & 0.47 & 30.08 & 1.08 & 0.46 & 1.64 \\
36 & 12.83 & 14.40 & 1.63 & 0.53 & 32.74 & 1.10 & 0.744 & 1.64 \\
47 & 12.54 & 14.63 & 1.69 & 0.49 & 29.10 & 1.20 & 0.61 & 1.75 \\
49 & 12.58 & 14.18 & 1.54 & 0.46 & 30.16 & 1.07 & 0.87 & 1.77 \\
52 & 14.22 & 15.73 & 2.14 & 0.54 & 25.05 & 1.61 & 0.69 & 1.73 \\
\hline Média & 13.15 & 14.97 & 1.84 & 0.523 & 28.60 & 1.32 & 0.68 & 1.82 \\
Máxima & 14.22 & 16.09 & 2.24 & 0.703 & 34.84 & 1.70 & 0.87 & 2.24 \\
Mínima & 12.17 & 13.87 & 1.47 & 0.419 & 21.97 & 1.05 & 0.46 & 1.64 \\
\hline
\end{tabular}


Figura 1. Rendimento médio de polpa por fruto (RP), expresso em percentagem, obtidos em quinze acessos de açaizeiro do tipo branco. Fonte: Autor.

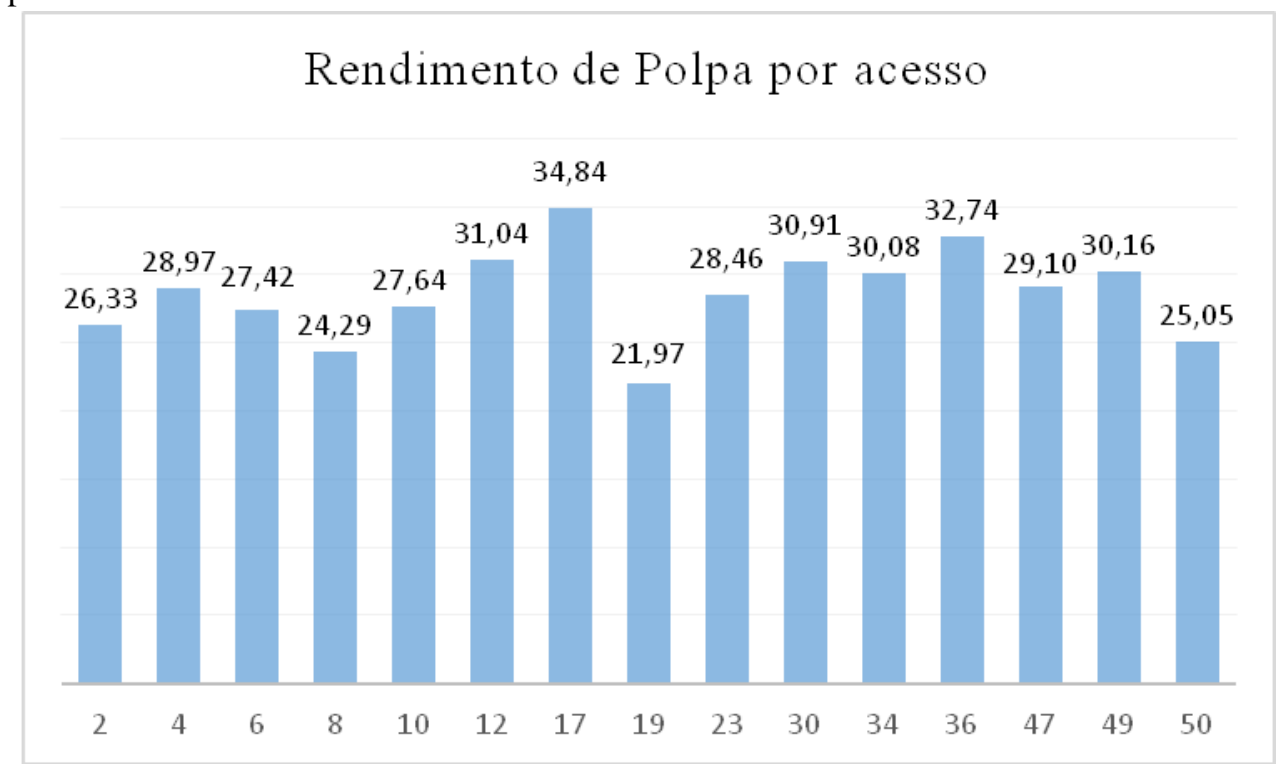

Quanto à coloração dos frutos, todos os acessos tiveram coloração verde, porém com três gradações, sendo o mais frequente $2,5 \mathrm{Y} 5 / 4$, com $53 \%$ de ocorrência para a cor da casca do fruto (Figura 2.A). No caso da polpa, a coloração predominante foi o verde que expressou duas variações, sendo mais frequente a 2,5Y 5/4 com 53\%, respectivamente (Figura 2.B).

Figura 2. Caracterização da cor da casca (A) e da polpa (B) em frutos maduros de quinze acessos de açaizeiro do tipo branco. Fonte: Autor

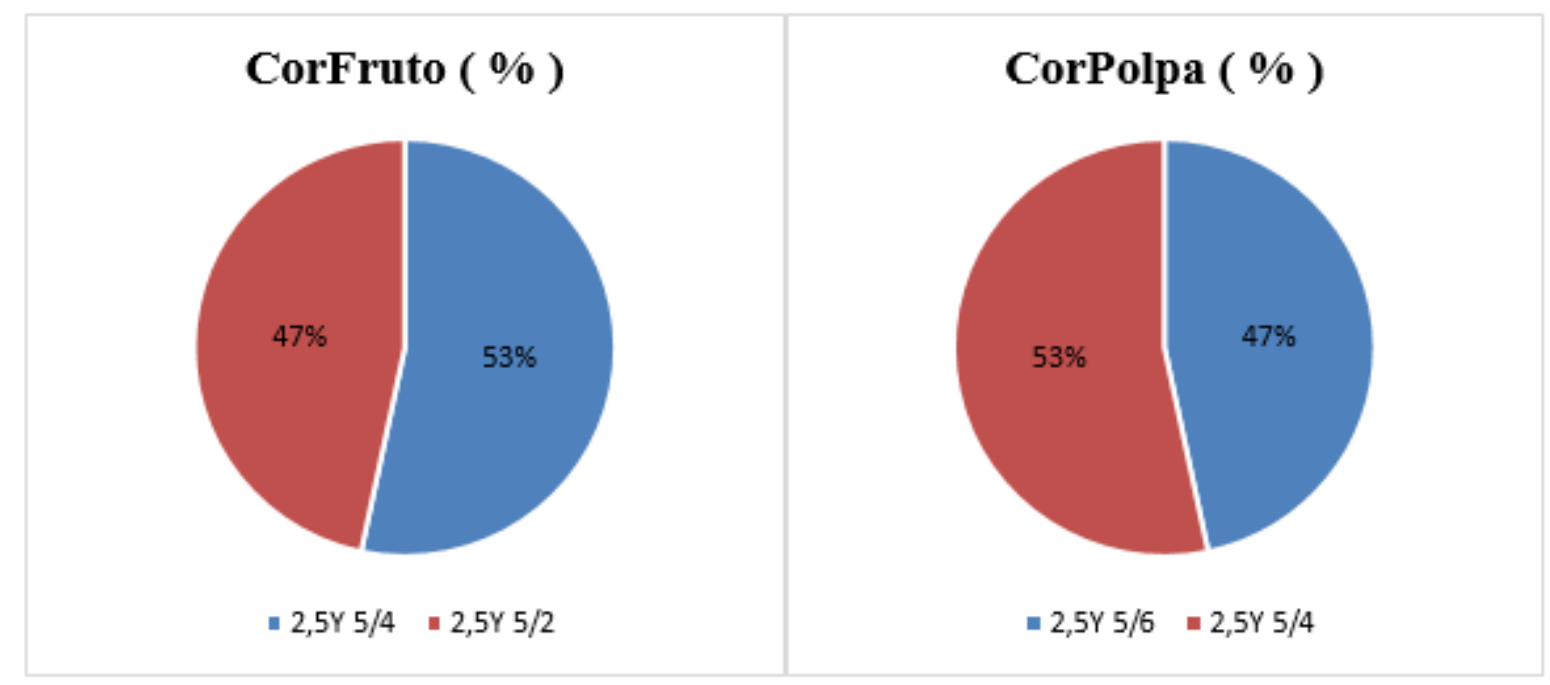




\section{Conclusões}

Os frutos de acessos de açaizeiro do tipo branco avaliados possuem pesos desejáveis e bons rendimentos de polpa para o atendimento de agroindústrias. Pelo menos três deles, reúnem as principais características ao mercado de polpa processada e a cor da polpa também apresenta variação que pode ser usada na classificação dos frutos.

\section{Referências}

BRANDAO, C. P.; OLIVEIRA, M. S. P. de . Avaliação e caracterização de frutos em acessos de patauazeiro. In: SEMINÁRIO DE INICIAÇÃO CIENTÍFICA, 18 e SEMINÁRIO DE PÓS GRADUAÇÃO, 2 DA EMBRAPA AMAZÔNIA ORIENTAL, Agosto, 2014, Belém, Pa.

CUNHA, C. R. ; MACIEL, V. T. ; MADRUGA, A. L. S. ; LUNZ, A. M. P. ; BERGO, C. L. ; OLIVEIRA, M. S. P. de . Caracterização físico-química da polpa de indivíduos experimentais de açaizeiro (Euterpe oleracea Mart.) com alta produtividade. In: CONGRESSO BRASILEIRO DE SISTEMAS AGROFLORESTAIS, 9, 2013, Ilhéus. Políticas públicas, educação e formação em SAF's na construção de paisagens sustentáveis. Ilhéus: CEPLAC, 2013. v. 1. p. 1-4.

NOGUEIRA, O.L.; FIGUEIRÊDO, F. J.C.; MÜlLER, A.A. Açaí. Belém, PA: Embrapa Amazônia Oriental, 2005. 137 p. (Embrapa Amazônia Oriental. Sistemas de produção, 4).

OLIVEIRA, M. do S. P. de; FARIAS NETO, J. T.de. Cultivar de açaizeiro para produção de frutos em terra firme: BRS-Pará. 2004.

OLIVEIRA, M. do S. P. de; CARVALHO, J. E. U. de; NASCIMENTO, W. M. O. do ; MULLER, Carlos Hans . Cultivo do açaizeiro para produção de frutos. Belém, PA: Embrapa Amazônia Oriental, 2002 (Circular Técnica).

OLIVEIRA, M. do S. P. de; FARIAS NETO, J. T. de; QUEIROZ, J.A.L de. Cultivo e manejo do Açaizeiro para Produção de Frutos. 2015.

OLIVEIRA, M. do S. P. Caracterização morfológica de frutos em acessos de tucumanzeiro (Astrocaryum vulgare Mart.). In: SIMPÓSIO DE RECURSOS GENÉTICOS PARA AMÉRICA LATINA E CARIBE, 3., 2001, Londrina. Anais... Londrina: IAPAR, 2001. p. 351. 